The Egyptian Journal of Hospital Medicine (January 2019) Vol. 74 (3), Page 524-533

\title{
Multifocal electroretinogram changes in Egyptians with axial high myopia
}

\author{
Abdullah A. El-Gamal*, Omar H. Salama, Adel A. Hassouna \\ Department of Ophthalmology, Faculty of Medicine, Al-Azhar University, Cairo, Egypt \\ *Corresponding author: Abdullah A. El-Gamal, email: drabdullahelgamal@ azhar.edu.eg,mobile: +201092793658
}

\begin{abstract}
Background: high myopia is a global burden that attracted researchers to its consequences. Although, there is few data regarding what high myopia causes to the normally appearing eyes. Effect of high myopia on retinal function can be detected by the multifocal electroretinography, which is capable of measuring and mapping retinal functions. Purpose: to measure changes in retinal functions in response to elongation of the axial length (AL). Patients and Methods: this is a descriptive study in which 15 patients aging 18-40 years with spherical equivalent (SE) of $\leq-5$ were included. A thorough ocular examination, including but not limited to visual acuity; best corrected visual acuity; anterior segment examination and fundus examination, was done and standard multifocal electroretinogram (mfERG) was performed. The measurements were taken in concentric rings and in quadrants, and then analyzed and statistically compared to normal readings of the matching age group. Results: a total of 30 eyes those were completely normal except for long AL with normal or tessellated fundi. The mfERG showed varying reductions in amplitudes (amp.) as well as elongations of implicit times (Imp.T), of both P1 and N1 components, at almost all rings and quadrants. Conclusion: retinal functions at different layers were significantly affected by extension of the AL, and that increases as the axial length increases. Recommendations: future studies should consider high myopia in normally appearing eye as well as in Egyptians to detect any special pattern of retinal function affection for that ethnicity.

Keywords: Multifocal electroretinogram, axial length, high myopia, retinal function, Egypt.
\end{abstract}

\section{Introduction:}

Researchers argued the definition of high myopia, with a spherical equivalent of -5.00 diopter (D) or less as the most agreed definition. High myopia is a great challenge because, it exposes the eye towards pathological changes and complications such as, but not limited to, glaucoma; retinal detachment (RD); macular degeneration; and cataract ${ }^{(\mathbf{1})}$. The pathological consequences rise in $30-50 \%$ of highly myopic patients, and those pathologies have taken attention of lots of studies. However, studies lack enough information about high myopia in otherwise normal eyes ${ }^{(2)}$.

The multifocal electroretinogram (mfERG) is a new recoding technique for retinal function, which is capable of measuring functions of multiple retinal locations, within the central 40$50 \%$, simultaneously. Its ability to make a topography of retinal functions and/or lesions has lent it a privilege over the other retinography techniques ${ }^{(3)}$.
There is consensus between studies that the mfERG response is negatively affected in myopia. Almost all studies reported decreased amplitudes and elongated implicit times, and that these changes intensify as the degree of myopia increases (4). In addition, myopia is mainly due to the axial component, with the refractive part playing a minor role ${ }^{(5)}$.

Studies showed no doubt that retinal function, mfERG response, reduces with elongation of the axial length. However, there were different results regarding the most affected location and/or interpretation of the analysis of the cause $(5,6,7,8)$.

As mfERG is influenced by ethnicity ${ }^{(9)}$ and there is scanty of data about effect of axial high myopia on the mfERG response in Egyptians. Therefore, this study provides additional data regarding that issue. 


\section{Aim of work}

The aim of the work is to evaluate mfERG changes in Egyptians with axial, non-refractive, high myopia and correlate changes to the axial length. The objectives are: (1) define axial, nonrefractive, myopia. (2) evaluate mfERG changes in axial, high myopia. (3) correlate mfERG changes to the axial length. (4) formulate recommendations based on the results.

\section{Patients and Methods}

Study design: descriptive, observational study. This study was conducted according to the World Medical Association's declaration of Helsinki and ethically approved by the Ethics Committee of Al-Azhar Faculty of Medicine.

Patients criteria: Among 25 patients randomly selected for the study, 2 refused to be included and 8 had fundus changes that are not compatible with the study. So, this study was carried out on 15 patients who attended the refractive unit, Ophthalmology department, hospitals of Al-Azhar University of Cairo between June 2018 and December 2018. All included patients (males and females) were aging from 18 to 40 years, with high myopia of 5.00 diopter (D) or less and axial length of 26 $\mathrm{mm}$ or more. Those who refused to consent as well as those having any opaque media or any retinal lesion except for tessellated fundus were excluded.

Evaluation: All participants were evaluated for visual acuity (VA) using the Snellen's chart; refraction using Topcon auto refractometer, model KR-800PA; best corrected visual acuity (BCVA) with trial glasses and lenses in place on the Snellen's chart; intra-ocular pressure (IOP) using Topcon, model CT 80, using the air-puff technique; color vision using Ishihara test; anterior segment examination (for any media opacity) using the Topcon slit-lamp, model SLD701; posterior segment examination (for any fundus abnormalities) using the slit-lamp with Hruby 90D and 78D lenses; the axial length (AL) using the Topcon Aladdin biometer with corneal topography. Written informed consents were taken from the patients.

Technical parameters: The multifocal electroretinogram (mfERG) was recorded, according to the International Society of the
Clinical Electrophysiology of Vision (ISCEV), using the Reti-port/Scan 21 system (Roland Consult, Germany). The stimulus was delivered on a 20-inch Cathode ray tube (CRT) monitor presenting 61 hexagons in the pseudo-binary msequence with a frame rate of $60 \mathrm{Hertz}(\mathrm{Hz})$ at distance of $33 \mathrm{~cm}$ and viewing angle of 27 degrees. The maximum luminance was $120 \mathrm{~cd} / \mathrm{m}^{2}$ for the white stimulus and $2 \mathrm{~cd} / \mathrm{m}^{2}$ for black stimulus. The active corneal electrode was the HK-loop electrode and was put in the lower fornix, the reference electrode was put on the skin near the ipsilateral outer canthus and the ground electrode was put on the forehead. The impedance was kept below $5 \mathrm{~K}$ Ohm.

Clinical protocol: All patients were tested at 11 AM to avoid the effect possibility of circadian rhythm. Patients were adapted to moderate to dim room light for $15 \mathrm{~min}$ before the test with the pupils fully dilated to more than $7 \mathrm{~mm}$ with $1.0 \%$ tropicamide hydrochloride. Patients were facing the middle of the screen and best-corrected for the distance. Anesthetic drop of topical benoxinate hydrochloride $0.4 \%$ was instilled. Patients were binocularly tested for 6 min with break at every $45 \mathrm{sec}$ and monitored for fixation by a camera attached to the screen.

Interpretation of the results: P1 amplitude was measured from the trough of the A1 to the peak of the P1; P1 implicit time was measured from the start of the stimulus to the peak of the P1 wave. N1 amplitude was measured from the baseline to the trough of the N1; N1 implicit time was measured from the start of the stimulus to the N1's trough. Summed responses were taken in concentric rings around the fovea, with areas $\left(\mathrm{deg}^{2}\right)$ of $12.6 ; 17.9 ; 26.2 ; 36.5$ and 48.6. Scaled amplitudes, as more accurate, were taken, and the response was divided into 4 quadrants (Q1 the superior nasal; Q2 superior temporal; Q3 inferior temporal; Q4 inferior nasal) around the fovea.

Statistical analysis: Responses between different rings and between different quadrants were collected into Excel sheets and statistically analyzed using the Statistical analysis software (SAS) v9.4 and Minitab software v18. Student ttest was done in SAS to obtain significance of statistical data. In addition, Pearson correlation and Regression analysis formula was done in 
Minitab to find types of relations and compare values, respectively. Significance was determined by a P-value of 0.05 or less.

\section{Results}

Among 25 patients randomly selected for the study, 2 refused to be included and 8 had fundus changes that are not compatible with the study. Therefore, we had 15 patients as plotted in table (1); 10 males and 5 females, with eye numbers of 30 . Their mean age was $30.7 \mathrm{y} \pm 5.2$ standard deviation (SD). Their mean myopic spherical equivalent (S.E) was $-12.9 \mathrm{D} \pm 3.5 \mathrm{SD}$. Their mean axial length (AL) was $28.33 \mathrm{~mm} \pm$ $0.96 \mathrm{SD}$. The range for the S.E and the AL was $8.78 \mathrm{D}$ and $2.72 \mathrm{~mm}$, respectively.

Table (1): Different parameters among groups

\begin{tabular}{|c|c|c|}
\hline & Emmetropia & High myopia \\
\hline Number of subjects & 15 & 15 \\
\hline Number of eyes & 30 & 30 \\
\hline Age (y) & $21: 39$ & $19: 38$ \\
\hline Sex & $7 \mathrm{M}: 8 \mathrm{~F}$ & $10 \mathrm{M}: 5 \mathrm{~F}$ \\
\hline Axial length (mm) & $23.2 \pm 0.79$ & $28.3 \pm 1$ \\
\hline Refraction (D) & $(+0.25:-0.25) \pm(-0.1:+0.1)$ & $-12.9 \pm 3.2$ \\
\hline
\end{tabular}

There are a range of changes as follows (table 2):

Table (2): Range of changes in participants

\begin{tabular}{|c|c|c|c|c|c|c|c|}
\hline \multicolumn{2}{|c|}{ P1 amp. $(\mu \mathrm{V})$} & \multicolumn{3}{|c|}{ P1 Imp.T (ms) } & \multicolumn{2}{|l|}{ N1 amp. $(\mu \mathrm{V})$} & N1 Imp.T (ms) \\
\hline & Range \pm SD & & Range \pm SD & & Range \pm SD & & Range \pm SD \\
\hline \multicolumn{8}{|c|}{ Rings } \\
\hline R1 & $1.43 \pm 0.5$ & R1 & $15.7 \pm 5.7$ & R1 & $0.77 \pm 0.31$ & R1 & $9.8 \pm 3.2$ \\
\hline $\mathbf{R 2}$ & $1.02 \pm 0.4$ & $\mathbf{R 2}$ & $10.8 \pm 4$ & $\mathbf{R 2}$ & $0.54 \pm 0.22$ & $\mathbf{R 2}$ & $12.8 \pm 4.8$ \\
\hline R3 & $0.81 \pm 0.3$ & R3 & $8.8 \pm 3.4$ & R3 & 0.334 v 0.13 & R3 & $6.8 \pm 2.5$ \\
\hline R4 & $0.51 \pm 0.2$ & R4 & $8.9 \pm 3.6$ & R4 & $0.28 \pm 0.09$ & R4 & $4.9 \pm 2.3$ \\
\hline R5 & $0.2 \pm 0.07$ & R5 & $4.7 \pm 2$ & R5 & $0.15 \pm 0.05$ & R5 & $3.9 \pm 1.7$ \\
\hline \multicolumn{8}{|c|}{ Quadrants } \\
\hline Q1 & $0.39 \pm 0.15$ & Q1 & $6.9 \pm 2.6$ & Q1 & $0.19 \pm 0.07$ & Q1 & $3.9 \pm 1.57$ \\
\hline Q2 & $0.48 \pm 0.2$ & Q2 & $8.9 \pm 3.15$ & Q2 & $0.3 \pm 0.1$ & Q2 & $4.8 \pm 2.24$ \\
\hline Q3 & $0.82 \pm 0.3$ & Q3 & $8.9 \pm 3.4$ & Q3 & $0.49 \pm 0.19$ & Q3 & $5.9 \pm 2.2$ \\
\hline Q4 & $0.41 \pm 0.14$ & Q4 & $6.9 \pm 2.6$ & Q4 & $0.16 \pm 0.05$ & Q4 & $11.7 \pm 4.6$ \\
\hline
\end{tabular}

Ring analysis

The P1 amplitudes $(\mu \mathrm{V})$ were negatively correlated with the axial length; the longer the axial length, the more reduced is the amplitude. That correlation was significant for the rings 1,2,3,4 and 5 with P-values of 0.001, 0.001, 0.0001, 0.0001, 0.0001, respectively (table 3).

Table (3): Rings $P 1$ amplitudes $\left(\mu \mathrm{V} / \mathrm{deg}^{2}\right)$

\begin{tabular}{|c|c|c|c|c|}
\hline & $\begin{array}{c}\text { Emmetropia } \\
(\text { Mean } \pm \text { SD) }\end{array}$ & $\begin{array}{c}\text { Axial myopia } \\
\text { (Mean } \pm \text { SD) }\end{array}$ & $\begin{array}{c}\text { Percentage } \\
\text { of change }\end{array}$ & P-value \\
\hline Ring 1 & $1.655 \pm 0.33$ & $0.68 \pm 0.5$ & $-59 \%$ & 0.001 \\
\hline Ring 2 & $1.335 \pm 0.26$ & $0.52 \pm 0.4$ & $-61 \%$ & 0.001 \\
\hline Ring 3 & $1.255 \pm 0.34$ & $0.5 \pm 0.32$ & $-60 \%$ & 0.0001 \\
\hline Ring 4 & $1.32 \pm 0.30$ & $0.44 \pm 0.2$ & $-67 \%$ & 0.0001 \\
\hline Ring 5 & $1.185 \pm 0.30$ & $0.36 \pm 0.06$ & $-69 \%$ & 0.0001 \\
\hline
\end{tabular}


There were significant delays in the P1 peak times for the rings 2,3,4 and 5 with a P-values of $0.019,0.023,0.05,0.031$, respectively (table 4$)$. Although P1 peak time in ring 1 was changed, the change was not significant.

\begin{tabular}{|l|c|c|c|c|}
\hline & $\begin{array}{c}\text { Table (4): Rings P1 Imp.T (ms) } \\
\text { Axial myopia (Mean } \pm \\
\text { SD) }\end{array}$ & Percentage of change & P-value \\
\hline Ring 1 & $39.915 \pm 0.31$ & $50.3 \pm 5.7$ & $26 \%$ & 0.072 \\
\hline Ring 2 & $37.105 \pm 0.37$ & $47.5 \pm 4$ & $28 \%$ & 0.019 \\
\hline Ring 3 & $37.835 \pm 0.36$ & $46.9 \pm 3.3$ & $24 \%$ & 0.023 \\
\hline Ring 4 & $37.9 \pm 0.30$ & $46.03 \pm 3.6$ & $21 \%$ & 0.051 \\
\hline Ring 5 & $39.24 \pm 0.32$ & $45.85 \pm 2.05$ & $17 \%$ & 0.031 \\
\hline
\end{tabular}

The N1 amplitudes were also diminished as the axial length increases. Significant changes were detected in rings 2,3,4,5 but not in ring 1 . Their p-values are 0.004, 0.0001, 0.0001, 0.0001 and 0.099, respectively (table 5).

Table (5): Rings N1 amplitudes $\left(\mu \mathrm{V} / \mathrm{deg}^{2}\right)$

\begin{tabular}{|l|c|c|c|c|}
\hline & $\begin{array}{c}\text { Emmetropia (Mean } \pm \\
\text { SD) }\end{array}$ & $\begin{array}{c}\text { Axial myopia (Mean } \pm \\
\text { SD) }\end{array}$ & Percentage of change & P-value \\
\hline Ring 1 & $0.7 \pm 0.30$ & $0.47 \pm 0.31$ & $-33 \%$ & 0.099 \\
\hline Ring 2 & $0.605 \pm 0.33$ & $0.24 \pm 0.22$ & $-60 \%$ & 0.004 \\
\hline Ring 3 & $0.58 \pm 0.31$ & $0.22 \pm 0.13$ & $-62 \%$ & 0.0001 \\
\hline Ring 4 & $0.665 \pm 0.30$ & $0.17 \pm 0.09$ & $-74 \%$ & 0.0001 \\
\hline Ring 5 & $0.65 \pm 0.30$ & $0.16 \pm 0.05$ & $-76 \%$ & 0.0001 \\
\hline
\end{tabular}

The N1 peak times were also significantly delayed in all rings except ring 2 . The $\mathrm{p}$-values were $0.005,0.083,0.019,0.016,0.005$ for rings 1,2,3,4,5 respectively (table 6).

\begin{tabular}{|l|c|c|c|c|}
\hline & $\begin{array}{c}|c| \\
\text { Emmetropia (Mean } \pm \\
\text { SD) }\end{array}$ & $\begin{array}{c}\text { Axial myopia (Mean } \pm \\
\text { SD) }\end{array}$ & Percentage of change & P-value \\
\hline Ring 1 & $19.55 \pm 0.56$ & $30.6 \pm 3.2$ & $57 \%$ & 0.005 \\
\hline Ring 2 & $18.93 \pm 0.38$ & $27.3 \pm 4.8$ & $44 \%$ & 0.083 \\
\hline Ring 3 & $18.08 \pm 0.31$ & $25.8 \pm 2.5$ & $43 \%$ & 0.019 \\
\hline Ring 4 & $18.685 \pm 0.40$ & $27.3 \pm 2.3$ & $46 \%$ & 0.016 \\
\hline Ring 5 & $19.05 \pm 0.34$ & $29.1 \pm 1.7$ & $53 \%$ & 0.005 \\
\hline
\end{tabular}

\section{Quadrants analysis}

The P1 amplitudes $(\mu \mathrm{V})$ were negatively correlated with the axial length; the longer the axial length, the more reduced is the amplitude. That correlation was significant for the quadrants $1,2,3,4$ with P-values of $0.002,0.001,0.003,0.001$, respectively (table 7). 
Table (7): Quadrants P1 amplitudes ( $\left.\mu \mathrm{V} / \mathrm{deg}^{2}\right)$

\begin{tabular}{|l|c|c|c|c|}
\hline & $\begin{array}{c}\text { Emmetropia (Mean } \\
\pm \text { SD) }\end{array}$ & $\begin{array}{c}\text { Axial myopia (Mean } \pm \\
\text { SD) }\end{array}$ & $\begin{array}{c}\text { Percentage of } \\
\text { change }\end{array}$ & $\begin{array}{c}\text { P- } \\
\text { value }\end{array}$ \\
\hline Quadrant 1 & $0.875 \pm 0.30$ & $0.38 \pm 0.15$ & $-57 \%$ & 0.002 \\
\hline Quadrant 2 & $1 \pm 0.34$ & $0.47 \pm 0.2$ & $-53 \%$ & 0.001 \\
\hline Quadrant 3 & $1.025 \pm 0.31$ & $0.48 \pm 0.30$ & $-53 \%$ & 0.003 \\
\hline Quadrant 4 & $0.92 \pm 0.33$ & $0.34 \pm 0.13$ & $-63 \%$ & 0.001 \\
\hline
\end{tabular}

There were significant delays in the P1 peak times for the quadrants $1,2,4$ but not quadrant 3 with P-values of $0.032,0.031,0.03,0.102$, respectively (table 8 ).

Table (8): Quadrants P1 Imp.T (ms)

\begin{tabular}{|l|c|c|c|c|}
\hline & $\begin{array}{c}\text { Emmetropia (Mean } \\
\pm \text { SD) }\end{array}$ & $\begin{array}{c}\text { Axial myopia (Mean } \pm \\
\text { SD) }\end{array}$ & $\begin{array}{c}\text { Percentage of } \\
\text { change }\end{array}$ & $\begin{array}{c}\text { P- } \\
\text { value }\end{array}$ \\
\hline Quadrant 1 & $39 \pm 0.32$ & $46.2 \pm 2.6$ & $18 \%$ & 0.032 \\
\hline Quadrant 2 & $39.005 \pm 0.30$ & $46.8 \pm 3.15$ & $20 \%$ & 0.031 \\
\hline Quadrant 3 & $39.24 \pm 0.64$ & $45.8 \pm 3.4$ & $17 \%$ & 0.102 \\
\hline Quadrant 4 & $39.135 \pm 0.73$ & $46.35 \pm 2.6$ & $18 \%$ & 0.03 \\
\hline
\end{tabular}

The N1 amplitudes were significantly diminished as the axial length increases. Significant changes were detected in quadrants $1,2,3,4$ with p-values of $0.0001,0.0001,0.001,0.0001$, respectively (table 9).

Table (9): Quadrants N1 amplitudes ( $\left.\mu \mathrm{V} / \mathrm{deg}^{2}\right)$

\begin{tabular}{|l|c|c|c|c|}
\hline & $\begin{array}{c}\text { Emmetropia (Mean } \\
\mathbf{\pm} \text { SD) }\end{array}$ & $\begin{array}{c}\text { Axial myopia (Mean } \pm \\
\text { SD) }\end{array}$ & $\begin{array}{c}\text { Percentage of } \\
\text { change }\end{array}$ & $\begin{array}{c}\text { P- } \\
\text { value }\end{array}$ \\
\hline Quadrant 1 & $0.58 \pm 0.37$ & $0.18 \pm 0.06$ & $-69 \%$ & 0.0001 \\
\hline Quadrant 2 & $0.655 \pm 0.30$ & $0.2 \pm 0.1$ & $-71 \%$ & 0.0001 \\
\hline Quadrant 3 & $0.645 \pm 0.33$ & $0.22 \pm 0.18$ & $-65 \%$ & 0.001 \\
\hline Quadrant 4 & $0.6 \pm 0.31$ & $0.11 \pm 0.05$ & $-81 \%$ & 0.0001 \\
\hline
\end{tabular}

The N1 peak times were also significantly delayed in all quadrants except quadrant 4 . The pvalues were $0.004,0.025,0.01,0.106$, for quadrants $1,2,3,4$, respectively (table 10).

Table (10): Quadrants N1 Imp.T (ms)

\begin{tabular}{|l|c|c|c|c|}
\hline & $\begin{array}{c}\text { Emmetropia (Mean } \\
\pm \text { SD) }\end{array}$ & $\begin{array}{c}\text { Axial myopia (Mean } \pm \\
\text { SD) }\end{array}$ & $\begin{array}{c}\text { Percentage of } \\
\text { change }\end{array}$ & $\begin{array}{c}\text { P- } \\
\text { value }\end{array}$ \\
\hline Quadrant 1 & $18.815 \pm 0.36$ & $28.2 \pm 1.5$ & $50 \%$ & 0.004 \\
\hline Quadrant 2 & $18.845 \pm 0.32$ & $26.6 \pm 2.2$ & $42 \%$ & 0.025 \\
\hline Quadrant 3 & $19.12 \pm 0.57$ & $28.2 \pm 2.2$ & $47 \%$ & 0.01 \\
\hline Quadrant 4 & $18.85 \pm 0.38$ & $26.7 \pm 4.6$ & $42 \%$ & 0.106 \\
\hline
\end{tabular}


The relationship between normal values (the emmetropes) and axial high myopia is presented in the following figures. Figure 1: rings amplitudes; figure 2: rings implicit times; figure 3: quadrants amplitudes and figure 4: quadrants implicit times.

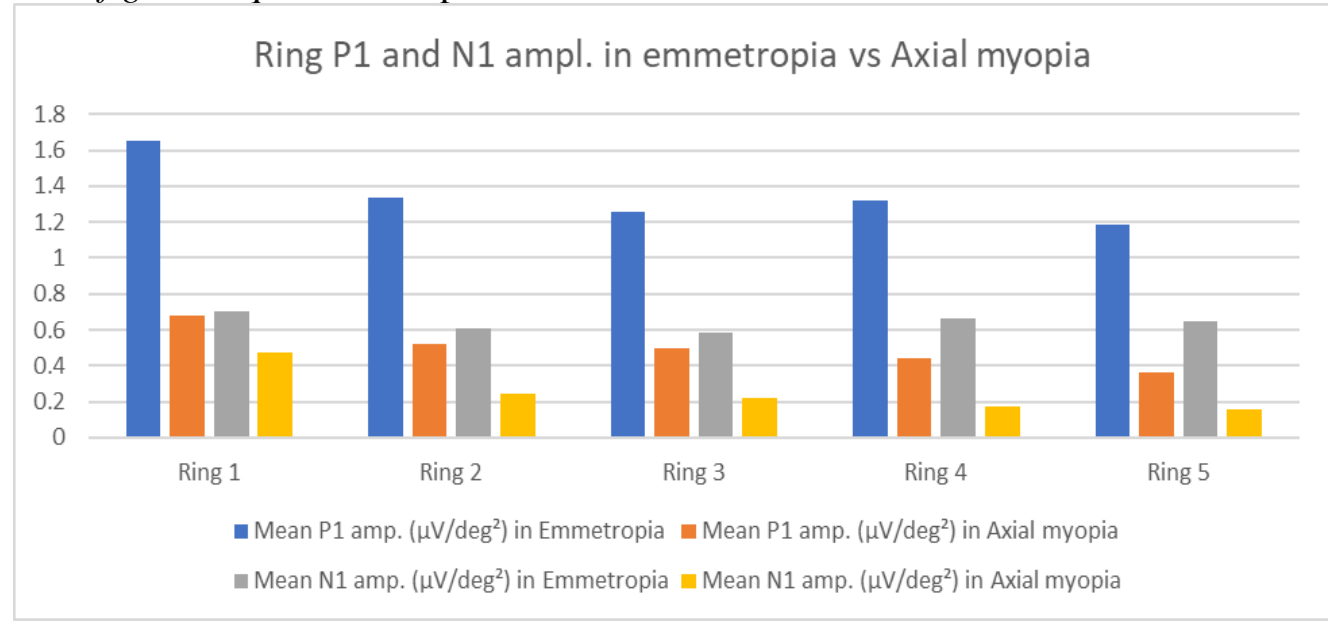

Figure 1: Ring P1 and N1 ampl. in emmetropia vs Axial myopia

\section{Ring P1 and N1 Imp.T in emmetropia vs Axial myopia}

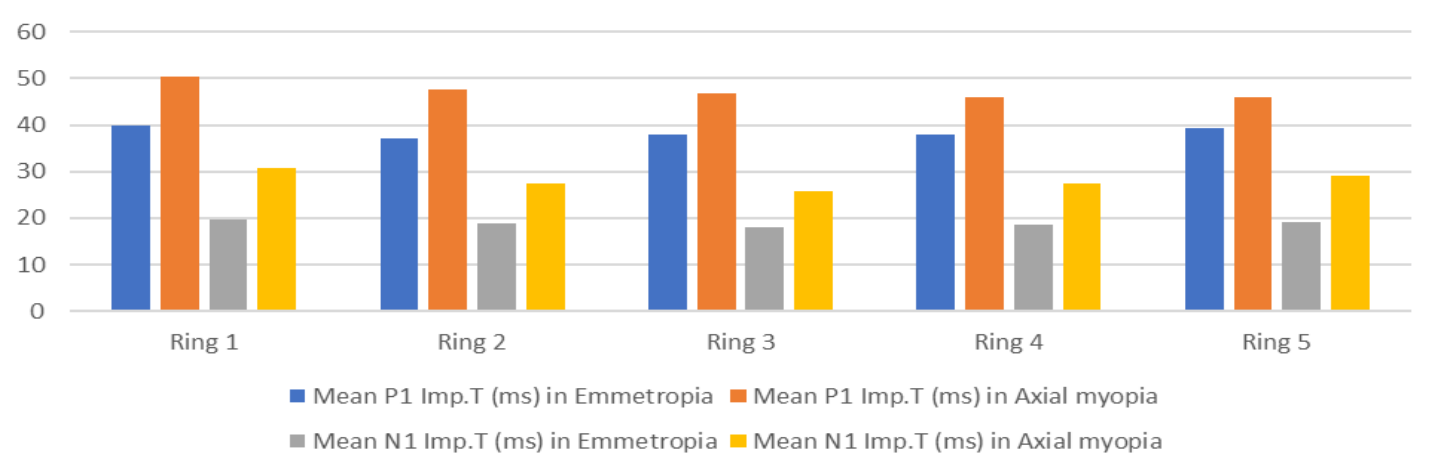

Figure 2: Ring P1 and N1 Imp.T in emmetropia vs Axial myopia

\section{Quadrant P1 and N1 ampl. in emmetropia vs Axial} myopia

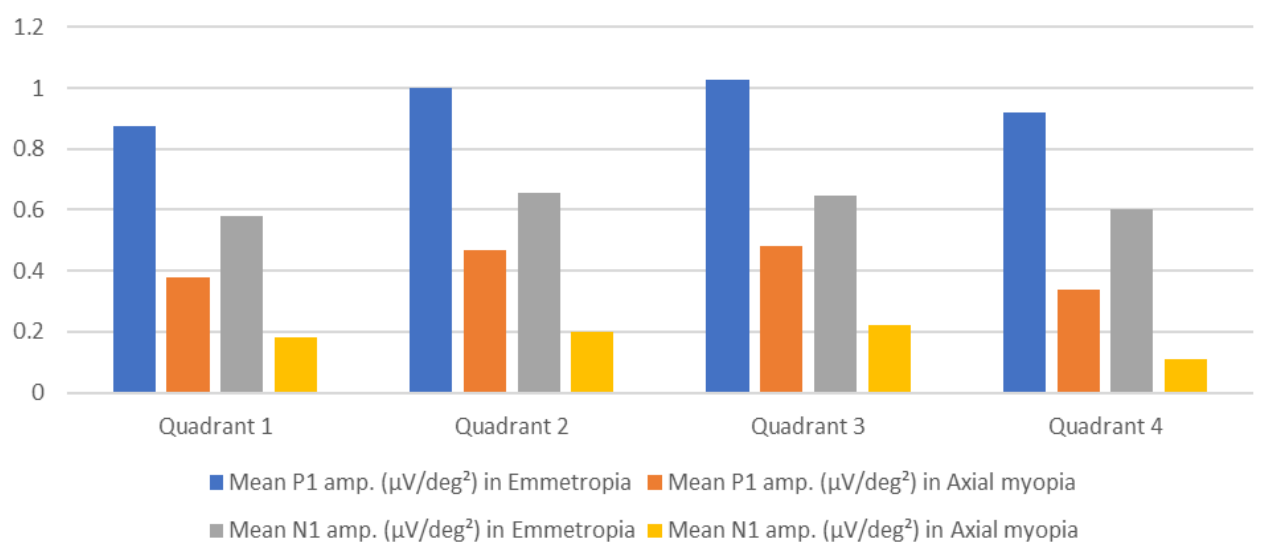

Figure 3: Quadrant P1 and N1 ampl. in emmetropia vs Axial myopia 


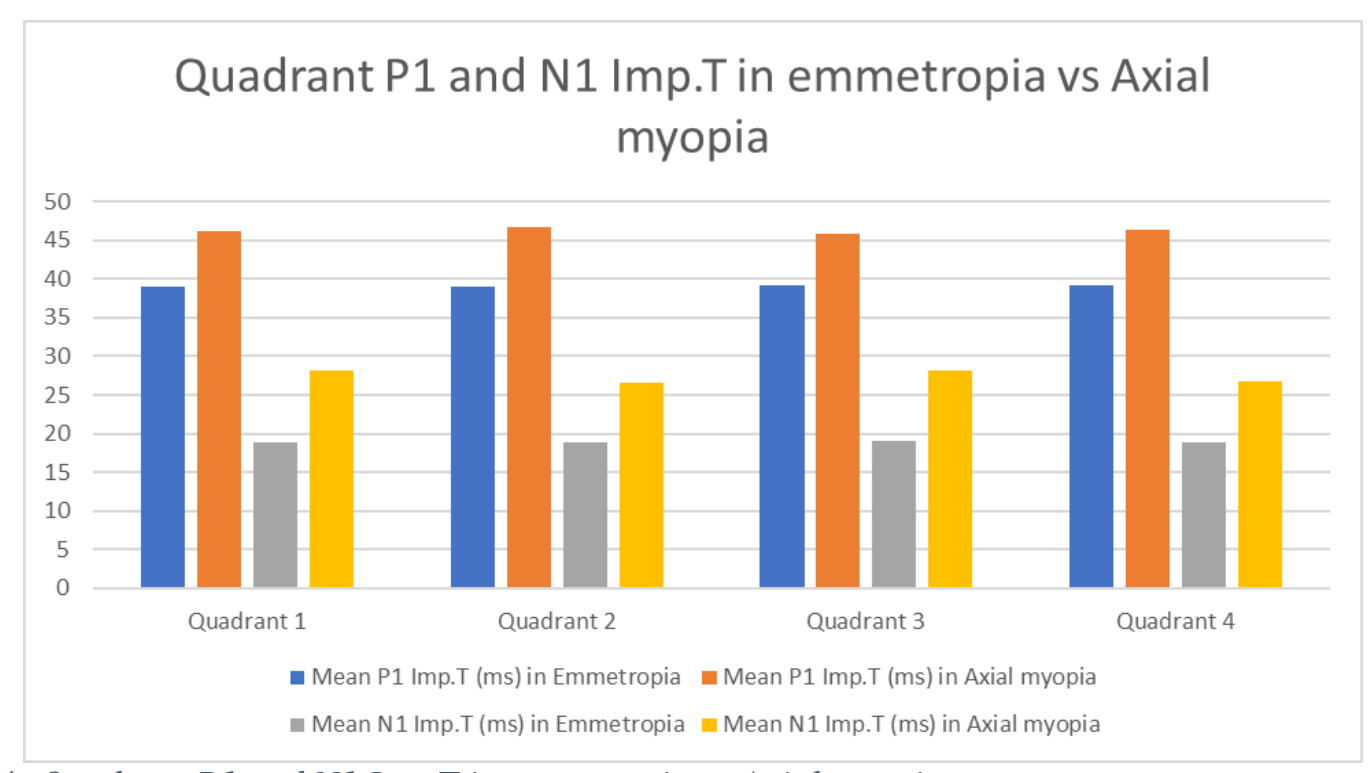

Figure 4: Quadrant P1 and N1 Imp.T in emmetropia vs Axial myopia

\section{Discussion:}

This study in the general frame was about high myopia, which spreading worldwide in a terrifying way. The number of highly myopic patients was 163 million or $2.7 \%$ of world population in the year 2000, and calculated to reach approximately 1 billion or $10 \%$ of world population by the year 2050 . In other words, the world will be up to 5-times increase in high myopic population by $2050^{(1)}$. There is lack of data about burden of high myopia in Egyptian population with only one study, as far as we know, estimated that pathological myopia affects $10.9 \%$ of Egyptians aging from $15-75$ years old, with $22.5 \%$ and $77.5 \%$ were unilaterally and bilaterally affected, respectively ${ }^{(\mathbf{1 0})}$.

The area of focus of this study was chosen because, studies lack enough information about high myopia in otherwise normal eyes ${ }^{(2)}$. In addition, the mfERG response is influenced by ethnicity ${ }^{(9)}$ and there is scanty of data about effect of axial high myopia on the mfERG response in Egyptians. Additionally, studies showed varying patterns of affection among different study groups ${ }^{(4,5,6,7)}$. Therefore, we aim to participate in making electrophysiological data about Egyptian population.

The patients were randomly selected and went through compete ocular evaluation and systemic assessment of any condition and/or medication that can affect the eye and/or the visual pathway, and if present, they were excluded from the study.

The lower cut of participants' age was 18 years because, it has been conducted that myopia progresses rapidly between 6-17 years old, after which that rate drops down dramatically. The age of 18-19 years is known as the age of refractive error stability because, the axial length and the posterior segment depth, being determinant of spherical refractive errors, have no change at this age nor afterwards. Additionally, astigmatism stabilizes at school age ${ }^{(\mathbf{1 1})}$. Another study pointed to the stability of refractive errors as dioptric change per decade ($0.6 \mathrm{D}$ in $20 \mathrm{~s} ;-0.39 \mathrm{D}$ in $30 \mathrm{~s} ;-0.29$ in $40 \mathrm{~s}$ ) ${ }^{(\mathbf{1 2})}$.

The upper cut of participants age was 40 years because, nuclear sclerosis of the lens is a normal aging process ${ }^{(\mathbf{1 3})}$ that starts mainly after age of 40 years ${ }^{(14)}$. In which, the increased density causes light scattering (15),(16) and that scattering increases as the density increases ${ }^{(17)}$.

Light scattering affects contrast sensitivity ${ }^{(\mathbf{1 8})}$, especially at night ${ }^{(\mathbf{1 9 )}}$, which is an age-related function ${ }^{(20,21)}$ that is influenced by many factors with opacification of the lens as a major player ${ }^{(\mathbf{2 2 2}, 23)}$. In addition, light scattering is inversely proportional to luminance and sensitivity. In turn, it affects retinal function, with varying results between studies ${ }^{(24,25,26)}$. In addition to light scattering, it has been found that nuclear sclerosis negatively affects all types of 
color perception at the center, while only the tritan was affected peripherally ${ }^{(\mathbf{1 6})}$. Color vision was evaluated because, it was conducted that response of the mfERG was significantly related to affection of color vision ${ }^{(27}{ }_{-}^{29)}$.

In other words, we included patients who had only long axial length in otherwise normal eyes, as we did not want our results confusing by any variable other than the one in focus.

The ISCEV parameters were applied to make results relatively comparable to results of other laboratories, and the 61-hexagon pattern was used obtain high signal to noise ratio and less time ${ }^{(30)}$. The pupils regulate the quantity of light passing into the eye. As so, it influences retinal illumination, and the mfERG accordingly (31) as it was reported that the amplitude diminished by more than 50\%; and the latency elongated by $8 \mathrm{~ms}$ for a $7 \mathrm{~mm}$ difference in diameter, with both central and peripheral affection ${ }^{(32)}$.

Studies, which investigated the relation between axial length and high myopia, showed no doubt that retinal function, mfERG response, reduces with elongation of the axial length. However, there were different results regarding the most affected location and/or interpretation of the analysis of the cause.

Sachidanandam et al. (6) reported significant reduction of the mfERG response with the increase of the axial length, with the center more affected than the periphery. They concluded more affection of the P1 amplitude than that of the N1. Also, peak times were more delayed as moving peripherally, though change in peak times with elongation of the axial length was not significant. They excluded abnormal signal transmission as a cause of this reduction in mfERG response. Chan and Mohidin (5) communicated central more than peripheral decrease in amplitude by $6-10 \%$ for each $\mathrm{mm}$ increase in axial length. However, peak times were only delayed significantly in some rings but not the others. They suggested morphological alterations as a cause behind the reduction in mfERG response. On contrast, Koh et al. ${ }^{(7)}$ reported peripheral affection more than in the center. Additionally, Kawabata and Udachi-Usami ${ }^{(8)}$ pointed the cause of reduction in mfERG with elongated axial length to disruption of cone function. On a study conducted, by Ismael $\boldsymbol{e t}$ al. ${ }^{(4)}$, on Egyptians, and they reported reduction of implicit times and prolongation of times at all rings and quadrants, however no preference for certain ring and/or quadrant response was reported.

In this study, we found central affection that increases with eccentricity, regarding ring amplitudes of both $\mathrm{P} 1$ and $\mathrm{N} 1$ waves. This is, in part, agrees with results of Koh et al. who reported only significant affection of the P1 amplitude peripherally. Although, it disagrees with results of Sachidanandam et al. ${ }^{(6)}$ who reported more affection centrally (compared to our more peripheral affection) and in being at all stimulated areas (compared to spare of $\mathrm{N} 1$ amplitude in the center in this study). Additionally, Chan and Mohidin (5) reported more central affection for both P1 and N1 components, which disagrees with our results.

On the other hand, ring implicit times of P1 were more affected in rings 1 and 4, while implicit times of $\mathrm{N} 1$ were more affected in rings 1 and 5. This study agrees, in part, regarding affection of $\mathrm{N} 1$ Implicit time in the central ring

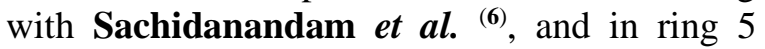
with Chan and Mohidin (5). However, it disagrees with these studies regarding the P1 implicit time, in which they reported no change. Moreover, this study agrees with Ismael et al. ${ }^{(4)}$ regarding affection of all components at almost all eccentricities.

The quadrant amplitudes were more affected in the inferior quadrants for the P1, while no much difference was found between quadrants regarding the $\mathrm{N} 1$ amplitude. On the other hand, implicit time of the P1 was less affected in the inferior temporal quadrant, while implicit time of $\mathrm{N} 1$ was less affected in the inferior nasal quadrant.

We believe that change in preference in ring and/or quadrant response, between this study and the mentioned studies, is not attributable to age differences among the participants. Because, those studies were made on participants aging between 15-27 years old except that of Ismael et al. ${ }^{(4)}$ from 15-35 years old, and they delivered varying patterns of response. On the other hand, the differences in response preference between this study and 
other studies may be pointed to ethnicity, as each study investigated different population. Supported by similarity of affection of all components in this study and the one conducted on Egyptians; same population.

The strength points of this study: (1) inclusion of normal or only tessellated fundi, with exclusion of any other fundus changes even myopic or not. (2) This study provides scientific community with more data about Egyptian population and how those data vary from other population.

Limitations to this study: (1) the study involved relatively small sample size. (2) the studied group lives in Cairo governorate and surroundings, which may be not an exact representative of the whole Egyptian population.

\section{Conclusion}

The extension of the axial length affects retinal function, negatively. All rings and quadrants amplitudes of the multifocal electroretinogram were significantly reduced except in ring 1 for $\mathrm{N} 1$ amplitude. Also, all ring and quadrants implicit times were elongated except in ring 1, ring 2, quadrant 3 and quadrant 4, for P1, N1, P1 and N1 Implicit times, respectively. Moreover, the strong correlation coefficients indicate that the higher the axial length, the more severely affected is the retinal function, but with varying strength of this relation at different ring and quadrants and regarding the wave or its values.

\section{Recommendations}

(1) further research on preventing high myopia is needed to as it severely damages visual function. (2) more research is required with the same focus of this study to confirm if Egyptian population has certain pattern of retinal function abnormalities in axial high myopia.

\section{Acknowledgement:}

We are thankful for Prof. Nazem A. Shalaby for his statistical support, Prof. Amira M. Elgohary and Ms. Omnia Nawara for their technical support.

\section{Disclosure:}

There is no conflict of interest for anyone of the authors, nor do they have any interest regarding the concluded results.

\section{References:}

1. Holden BA, Fricke TR, Wilson DA et al .(2016): Global Prevalence of Myopia and High Myopia and Temporal Trends from $2000 \quad$ through 2050. Ophthalmology, 123(5):1036-1042.

2. Jong M, Sankaridurg P, Li W et al. (2018): Reduced vision in highly myopic eyes without ocular pathology: the ZOCBHVI high myopia study. Clin. Exp. Optom., 101(1):77-83.

3. Lai TYY, Chan WM, Lai RYK et al. (2007): The Clinical Applications of Multifocal Electroretinography: A Systematic Review. Surv. Ophthalmol., 52(1):61-96.

4. Ismael ZF, El-Shazly AAE-F, Farweez YA et al .(2017): Relationship between functional and structural retinal changes in myopic eyes. Clin. Exp. Optom., 100:695-703.

5. Chan HL, Mohidin N (2003): Variation of multifocal electroretinogram with axial length. Ophthalmic Physiol. Opt., 23(2):133-140.

6. Sachidanandam R, Ravi P, Sen P (2017): Effect of axial length on full-field and multifocal electroretinograms. Clin. Exp. Optom., 100(6):668-675.

7. Koh V, Tan C, Nah G et al. (2014): Correlation of structural and electrophysiological changes in the retina of young high myopes. Ophthalmic Physiol. Opt., 34(6):658-666.

8. Kawabata H, Adachi-Usami E (1997): MULTIFOCAL ELECTRORETINOGRAM IN MYOPIA. Invest. Ophthalmol. Vis. Sci., 38(13):1256-1265.

9. Simão S, Costa MÂ, Sun JK et al. (2017): Development of a Normative Database for Multifocal Electroretinography in the Context of a Multicenter Clinical Trial. Ophthalmic Res., 57(2):107-117.

10. Elnahry AG, Khafagy MM, Esmat SM et al. (2018): Prevalence of pathological myopia among patients in a large tertiary care center in Egypt. New Front Ophthalmol., 4(5):1-4.

11. Lam CSY, Edwards M, Millodot M et al. (1999): A 2-year longitudinal study of 
myopia progression and optical component changes among Hong Kong schoolchildren. Optom. Vis. Sci., 76(6):370-380.

12. Nizam A, Ellingsen KL, Ellingsen BA et al. (1997): Age-related Refractive Shifts in Simple Myopia. J. Refract. Surg., 13(3):223-228.

13. Barber GW (1973): Human cataractogenesis: A review. Exp. Eye. Res., 16(2):85-94.

14. Klein B, Klein R, Linton $K$ (1992): Prevalence of Age-related Lens Opacities in a Population: The Beaver Dam Eye Study. Ophthalmology, 99(4):546-552.

15. Rouhiainen P, Rouhiainen H, Salonen JT (2009): Contrast sensitivity in different types of early lens opacities. Acta. Ophthalmol. Scand., 74(4):379-384.

16. Fristrom B, Lundh BL (2001): Colour contrast sensitivity in cataract and pseudophakia. Acta. Ophthalmol. Scand., 78(5):506-511.

17. Crnej A, Hirnschall N, Petsoglou C et al. (2017): Methods for assessing forward and backward light scatter in patients with cataract. J. Cataract Refract. Surg., 43(8):1072-1076.

18. Paulsson LE, Sjöstrand J (1980): Contrast sensitivity in the presence of a glare light. Theoretical concepts and preliminary clinical studies. Invest. Ophthalmol. Vis. Sci., 19(4):401-406.

19. Koch DD (1989): Glare and contrast sensitivity testing in cataract patients. J. Cataract Refract. Surg., 15(2):158-164.

20. Oshika T, Okamoto C, Samejima T et al. (2006): Contrast Sensitivity Function and Ocular Higher-Order Wavefront Aberrations in Normal Human Eyes. Ophthalmology, 113(10):1807-1812.

21. Ross JE, Clarke DD, Bron AJ(1985): Effect of age on contrast sensitivity function: uniocular and binocular findings. Br. J. Ophthalmol., 69(1):51-56.

22. Allard R, Renaud J, Molinatti S et al. (2013): Contrast sensitivity, healthy aging and noise. Vision Res., 92:47-52.

23. Grewal DS, Brar GS, Grewal SP (2009): Correlation of Nuclear Cataract Lens
Density Using Scheimpflug Images with Lens Opacities Classification System III and Visual Function. Ophthalmology, 116(8):1436-1443.

24. Tam A, Chan H, Brown B et al. (2004): The effects of forward light scattering on the multifocal electroretinogram. Curr. Eye. Res., 28(1):63-72.

25. Chan HL, Siu AW, Yap MK et al. (2002): The effect of light scattering on multifocal electroretinography. Ophthalmic Physiol. Opt., 22(6):482490.

26. Arai M, de Faria JML, Hirose T (1999): Effects of Stimulus Blocking, Light Scattering, and Distortion on Multifocal Electroretinogram. Jpn. J. Ophthalmol., 43(6):481-489.

27. Feigl B, Brown B, Lovie-Kitchin J et al .(2004): Cone-mediated multifocal electroretinogram in early age-related maculopathy and its relationships with subjective macular function tests. Curr. Eye Res., 29(4-5):327-336.

28. Rosenberg T, Baumann B, Kohl S et al. (2004): Variant Phenotypes of Incomplete Achromatopsia in Two Cousins with GNAT2 Gene Mutations. Investig. Opthalmology Vis. Sci., 45(12): 4256.

29. Tränkner D, Jägle H, Kohl S et al. (2004): Molecular basis of an inherited form of incomplete achromatopsia. J. Neurosci., 24(1):138-147.

30. Hood DC, Bach M, Brigell M et al. (2012): ISCEV standard for clinical multifocal electroretinography (mfERG) . Doc. Ophthalmol., 124(1):1-13.

31. Parks S, Keating D (2005): The multifocal electroretinogram. In: Handbook of Clinical Neurophysiology. Vol 5. Elsevier Ltd.

32. Gonzalez P, Parks S, Dolan F et al. (2004): The effects of pupil size on the multifocal electroretinogram. Doc. Ophthalmol., 109(1):67-72.

33. Hood DC(2000): Assessing Retinal Function with the Multifocal Technique. Prog. Retin. Eye Res., 19(5):607-647. 